\title{
ANALISIS NILAI TAMBAH AGROINDUSTRI TEPUNG TAPIOKA (Studi Kasus Pada Agroindustri Tepung Tapioka "Madur" di Desa Bojongasih Kecamatan Bojongasih Kabupaten Tasikmalaya)
}

\author{
SRI WANI NOPIANI ${ }^{1}$, TRISNA INSAN NOOR ${ }^{2}$, SUDRAJAT $^{1}$ \\ ${ }^{1}$ Fakultas Pertanian Universitas Galuh \\ ${ }^{2}$ Fakultas Pertanian Universitas Padjadjaran \\ *E-mail : sriwaninopiani07@gmail.com
}

\begin{abstract}
ABSTRAK
Penelitian ini bertujuan untuk menganalisis besarnya keuntungan dan nilai tambah yang diperoleh dalam usaha pengolahan ubi kayu menjadi tepung tapioka "Madur" di Desa Bojongasih Kecamatan Bojongasih Kabupaten Tasikmalaya. Penelitian ini dilakukan pada bulan Pebruari sampai dengan bulan Juli 2019. Penentuan daerah penelitian berdasarkan pertimbangan bahwa, di Desa tersebut terdapat agroindustri tepung tapioka. Informan yang diambil adalah satu orang, yaitu pemilik perusahaan. Hasil penelitian menunjukkan bahwa: 1) Usaha agroindustri tepung tapioka memberikan keuntungan sebesar Rp 2.623.506, per satu kali proses produksi.2). Besarnya nilai tambah agroindustri tepung tapioka adalah sebesar Rp 5.589 per kilogram bahan baku. Rasio nilai tambah terhadap nilai produk sebesar 77,6\%. Artinya untuk setiap $\mathrm{Rp} 100$ nilai produk akan diperoleh nilai tambah Rp 77. Nilai tambah menunjukkan nilai yang positif dan besar. Maka agroindustri tepung tapioka "Madur" sangat layak untuk diteruskan.
\end{abstract}

Kata Kunci: Agroindustri, Tepung Tapioka, Nilai Tambah

\section{ABSTRACT}

This study aims to analyze the amount of profit and added value obtained in the cassava processing business into "Madur" tapioca flour in Bojongasih Village, Bojongasih Subdistrict, Tasikmalaya Regency. This research was conducted in February to July 2019. Determination of the study area was based on the consideration that, in the village there were agro-processing industries of cassava into tapioca flour. The informant taken is one person, namely the owner of the company. The results of the study show that: 1) Cassava processing business into tapioca flour provides a profit of Rp 2.623.506, per one-time production process.2). The amount of tapioca flour agroindustry added value is Rp.5,589 per kilogram of raw material. The ratio of value added to product value is $77.6 \%$. This means that for every Rp. 100 the value of the product will be added to the value of $R p .77$. The added value shows a positive and large value. So the "Madur" tapioca flour agroindustry is very feasible to continue.

Keywords: Agroindustry, Tapioca Flour, Value Added

\section{PENDAHULUAN}

Negara Indonesia identik dengan sebutan negara agraris karena sebagian besar masyarakat Indonesia bermatapencaharian sebagai petani. Selain itu, Indonesia juga merupakan negara yang terkenal dengan kesuburan akan tanahnya, sehingga dimana saja menanam tanaman bisa tumbuh dengan subur. Pertanian merupakan sektor primer dalam perekonomian Indonesia yang artinya pertanian merupakan sektor utama yang menyumbang hampir dari setengah perekonomian yang berperan sebagai penghasil devisa negara melalui ekspor (Sjamsir, 2017).

Menurut Hayati (2017), sektor pertanian merupakan salah satu sektor 
yang sangat potensial dalam memberikan sumbangan terhadap ekonomi nasional bagi pendapatan tenaga kerja di Indonesia. Di Indonesia peranan pertanian sudah tidak diragukan lagi dalam pembangunannya.

Salah satunya yaitu dengan cara menjaga keseimbangan antar sektor pertanian dengan industri. Karena pada dasarnya perekonomian Indonesia masih akan tetap mengandalkan sektor industri, maka yang paling sesuai adalah pengolahan produk pertanian melalui pengembangan agroindustri.

Menurut Maulidah (2012), pengembangan agroindustri akan dapat meningkatkan permintaan hasil-hasil pertanian sehingga meningkatkan produksi, harga hasil pertanian dan pendapatan petani. Pengembangan sektor pertanian akan meningkatkan permintaan sektor agroindustri hulu, sektor pemasaran dan sektor penunjang lainnya. Dengan demikian, pengembangan sektor agroindustri mempunyai efek pengganda (multiplier effect) yang besar.

Menurut Setiawan (2012), agroindustri memiliki potensi yang sangat besar, potensinya meliputi $79 \%$ dari seluruh potensi dalam agribisnis. Pertanian di pedesaan identik dengan kemiskinan, artinya untuk mengentaskan kemiskinan di pedesaan memerlukan kreativitas bagi peningkatan nilai tambah hasil pertanian, alternatif lapangan pekerjaan dan pendapatan rumah tangga. Maka pengembangan agroindustri sangat diperlukan di pedesaan.

Salah satu keberhasilan dalam meningkatkan perekonomian di sektor pertanian adalah adanya kerjasama dengan berbagai kalangan baik itu petani dalam hal ini, maupun pihak pemerintah, dan pihak swasta sebagai pelaku industri. Dengan demikian, diharapkan mampu memecahkan masalah pertanian yang dihadapi sehingga mampu mensejahterakan petani.

Pertanian menjadi sangat penting karena adanya pengolahan hasil pertanian dengan berbagai pertimbangan, seperti meningkatkan penyerapan tenaga kerja, meningkatkan keterampilan pelaku industri serta meningkatkan pendapatan bagi pelaku industri. Bagi pelaku industri skala besar, dalam kegiatan pengolahan hasilnya pelaku industri menjadikannya sebagai hal utama dalam usahanya. Hal ini disebabkan karena dengan cara pengolahannya yang baik, maka nilai tambah dalam produk pertanian semakin tinggi dan mampu menerobos hingga ke pasar luar negeri.

Nilai tambah adalah pertambahan nilai suatu komoditas yang berupa proses pengubahan bentuk (form utility), 
pemindahan tempat (place utility), maupun proses penyimpanan (time utility) (Hamidah, 2015).

$$
\text { Nilai tambah sendiri }
$$

menggambarkan tingkat kemampuan menghasilkan pendapatan di suatu wilayah, dan nilai tambah mampu mengatur masyarakat agar hidup makmur.

Tanaman ubi kayu adalah komoditi pertanian yang dipakai untuk bahan makanan. Ubi kayu masih memberikan hasil bahkan pada tanah yang kurang subur, dimana pada tanaman lainnya tidak dapat memberikan hasil. Tanaman ubi kayu mudah menyesuaikan di tempat tumbuhnya, baik dalam lahan yang subur ataupun dalam lahan yang tidak subur (Suprapti, 2005).

Salah satu agroindustri yang dikembangkan di Kabupaten Tasikmalaya yaitu industri tepung tapioka. Salah satu industri tepung tapioka yang ada di Kabupaten Tasikmalaya yaitu ada di Desa Bojongasih, industri pengolahannya terdiri atas pengolahan tepung tapioka dan pabrik penggilingan tapioka kasar untuk diproses menjadi tepung tapioka halus yang siap untuk dipasarkan.

Berdasarkan data dari Disperindag Kabupaten Tasikmalaya (2017) terdapat beberapa agroindustri tepung tapioka di Kabupaten Tasikmalaya, sebagaimana dapat dilihat pada Tabel 1 .

\section{Tabel 1. Data Agroindustri Tepung Tapioka di Kabupaten Tasikmalaya Tahun 2017}

\begin{tabular}{|c|c|c|c|c|c|c|}
\hline $\begin{array}{c}\text { No } \\
\cdot \\
\end{array}$ & Nama Perusahaan & $\begin{array}{c}\text { Nama } \\
\text { Pengusaha }\end{array}$ & Kecamatan & Desa & $\begin{array}{l}\text { Nilai Investasi } \\
\text { (Rp) }\end{array}$ & $\begin{array}{c}\text { Tenaga } \\
\text { Kerja } \\
\text { (Orang) }\end{array}$ \\
\hline 1. & Karya Subur Sentosa & Lieo Jin & Manonjaya & Cilangkap & 1.000 .000 .000 & 26 \\
\hline 2. & - & Karta & Cineam & Cijulang & 8.500 .000 & 5 \\
\hline \multirow{2}{*}{$\begin{array}{l}3 . \\
4 .\end{array}$} & Aneka Jaya & Solehudin & Jatiwaras & Kertahayu & 17.000 .000 & 7 \\
\hline & Pabrik Aci Cinunjang & $\begin{array}{c}\text { H. Ujo } \\
\text { Johar } \\
\text { Aripin }\end{array}$ & $\begin{array}{l}\text { Gunung } \\
\text { Tanjung }\end{array}$ & Cinunjang & 22.000 .000 & 15 \\
\hline \multirow{3}{*}{$\begin{array}{l}5 . \\
6 . \\
7 .\end{array}$} & - & Harun Spd & Cineam & Cikondang & 10.000 .000 & 5 \\
\hline & Cahaya Murni & $\begin{array}{l}\text { H. Oyon } \\
\text { Joni }\end{array}$ & Cineam & Cikondang & 18.500 .000 & 10 \\
\hline & Pabrik Aci Madur & $\begin{array}{c}\text { Tendi } \\
\text { Sasmita }\end{array}$ & Bojongasih & Bojongasih & 2.000 .000 .000 & 28 \\
\hline 8. & $\begin{array}{c}\text { Perusahaan Aci } \\
\text { Singkup }\end{array}$ & $\begin{array}{c}\text { Cecep } \\
\text { Kustiawan }\end{array}$ & Jatiwaras & Setiawangi & 20.000 .000 & 8 \\
\hline 9. & - & $\begin{array}{c}\text { Ikin } \\
\text { Sanjaya }\end{array}$ & $\begin{array}{c}\text { Karang } \\
\text { Nunggal }\end{array}$ & $\begin{array}{l}\text { Karang } \\
\text { Nunggal }\end{array}$ & 32.500 .000 & 14 \\
\hline 10 & - & $\begin{array}{c}\text { Tatang } \\
\text { D.H }\end{array}$ & Cineam & Nagaratengah & & \\
\hline
\end{tabular}

Sumber : Dinas Perindustrian dan Perdagangan Kabupaten Tasikmalaya, 2017

Berdasarkan Tabel 1 diketahui bahwa nilai investasi terbesar agroindustri tepung tapioka di Kabupaten Tasikmalaya yaitu pada agroindustri tepung tapioka 
"Madur" di Desa Bojongasih dengan nilai investasi Rp. 2.000.000.000 dan tenaga kerja sebanyak 28 orang. Berdasarkan survey awal, diketahui bahwa agroindustri tepung tapioka "Madur" yang berlokasi di Desa Bojongasih merupakan satu-satunya perusahaan agroindustri yang masih tetap berdiri dari tahun 1988 hingga saat ini. Perusahaan agroindustri tepung tapioka "Madur" dapat dikatakan strategis karena memiliki sumber air dan akses sumber matahari yang baik untuk melaksanakan produksi. Sumber air dan matahari sangat dibutuhkan bagi agroindustri tepung tapioka sehingga sangat mendukung keberhasilan usaha industri tepung tapioka dan memiliki tempat pembuangan limbah dari pemukiman penduduk sangat jauh sehingga tidak memberikan dampak buruk bagi masyarakat sekitar. Dan pemilik perusahaan tetap mempertahankan agroindustri tepung tapioka selama 31 tahun lamanya karena kebutuhan akan tepung tapioka semakin meningkat dari tahun ke tahun, yang disebabkan oleh banyaknya pembuat makanan dari bahan dasar tepung tapioca. Meskipun banyak petani yang kurang minat dalam berusahatani ubi kayu dan banyaknya perusahaan agroindustri yang gulung tikar. Oleh karena itu penulis tertarik untuk melakukan penelitian mengenai “Analisis
Nilai Tambah Agroindustri Tepung Tapioka" yang merupakan studi kasus pada agroindustri tepung tapioka "Madur" di Desa Bojongasih Kecamatan Bojongasih Kabupaten Tasikmalaya.

\section{METODE PENELITIAN}

Jenis penelitian yang digunakan adalah studi kasus, pada agroindustri tepung tapioka "Madur" di Desa Bojongasih Kecamatan Bojongasih Kabupaten Tasikmalaya. Menurut Rahardjo \& Gudnanto (2011), studi kasus adalah suatu metode untuk memahami individu yang dilakukan secara integratif dan komprehensif agar diperoleh pemahaman yang mendalam tentang individu tersebut beserta masalah yang dihadapinya

\section{TEKNIK PENGUMPULAN DATA}

Menurut Sugiyono (2018 untuk mendapatkan data adalah untuk mendapatkan data. Data yang digunakan dalam penelitian ini adalah:

1. Diperoleh dari data primer adalah data yang diperoleh melalui wawancara dengan pemilik perusahaan berdasarkan kuesioner yang telah disiapkan, serta melakukan pengamatan langsung di lapangan. Data primer terdiri dari data bahan baku (ubi kayu), biayabiaya yang dikeluarkan untuk melakukan produksi tepung tapioka, 
jumlah tenaga kerja, serta keuntungan dalam memproduksi tepung tapioka.

2. Data Sekunder diperoleh dari dinas atau intansi yang berkaitan dengan penelitian ini. Data sekunder terdiri atas data yang diambil dari Dinas Perindustrian dan Perdagangan, beserta intansi lainnya. Serta diperoleh dari buku dan literatur yang berkaitan dengan penelitian ini.

\section{TEKNIK PENARIKAN SAMPEL}

Desa Bojongasih dipilih dengan pertimbangan nilai investasi paling tinggi di Kabupaten Tasikmalaya.

Teknik pemilihan informan dalam penelitian ini dilakukan secara sengaja (Purposive Sampling) yaitu pada seorang pengusaha agroindustri tepung tapioka "Madur" di Desa Bojongasih Kecamatan Bojongasih Kabupaten Tasikmalaya. Teknik pemilihan informan berdasarkan tujuan riset. Sedangkan orang-orang yang dalam populasi yang tidak sesuai dengan kriteria tersebut tidak dijadikan sampel (Krisyantono, 2006).

\section{RANCANGAN ANALISIS DATA}

1. Biaya total agroindustri tepung tapioka dihitung dengan menggunakan rumus menurut Suratiyah (2015) sebagai berikut:
$\mathrm{TC}=\mathrm{FC}+\mathrm{VC}$

Dimana

$\mathrm{TC}=$ Total Cost (Biaya Total)

$\mathrm{FC}=$ Fixed Cost (Biaya Tetap)

$\mathrm{VC}=$ Variable Cost (Biaya Variabel)

2. Penerimaan agroindustri tepung tapioka dihitung dengan menggunakan rumus menurut Suratiyah (2015) sebagai berikut:

$\mathrm{P}=\mathrm{Y}$. Py

Dimana :

$\mathrm{P}=$ Total penerimaan

$\mathrm{Y}=$ Jumlah produksi

Py $=$ Harga produksi

3. Pendapatan agroindustri tepung tapioka dihitung dengan menggunakan rumus menurut Suratiyah (2015) sebagai berikut:

$\mathrm{I}=\mathrm{P}-\mathrm{TC}$

Dimana:

$\mathrm{I}=$ Pendapatan

$\mathrm{P}=$ Penerimaan

$\mathrm{TC}=$ Total Cost (Biaya Total)

4. Analisis Nilai Tambah dihitung menggunakan metode Hayami dalam Maulidah (2012), yang memperkirakan perubahan nilai bahan baku setelah mendapatkan perlakuan. Nilai tambah yang terjadi dalam proses pengolahan merupakan selisih dari nilai produk dengan biaya bahan baku dan input lainnya. 
Format (prosedur) perhitungan nilai tambah menurut Hayami secara lengkap disajikan pada Tabel 5.
Format (prosedur) perhitungan nilai tambah menurut Hayami secara lengkap disajikan pada Tabel 5.

\section{Tabel 2. Perhitungan Nilai Tambah Metode Hayami}

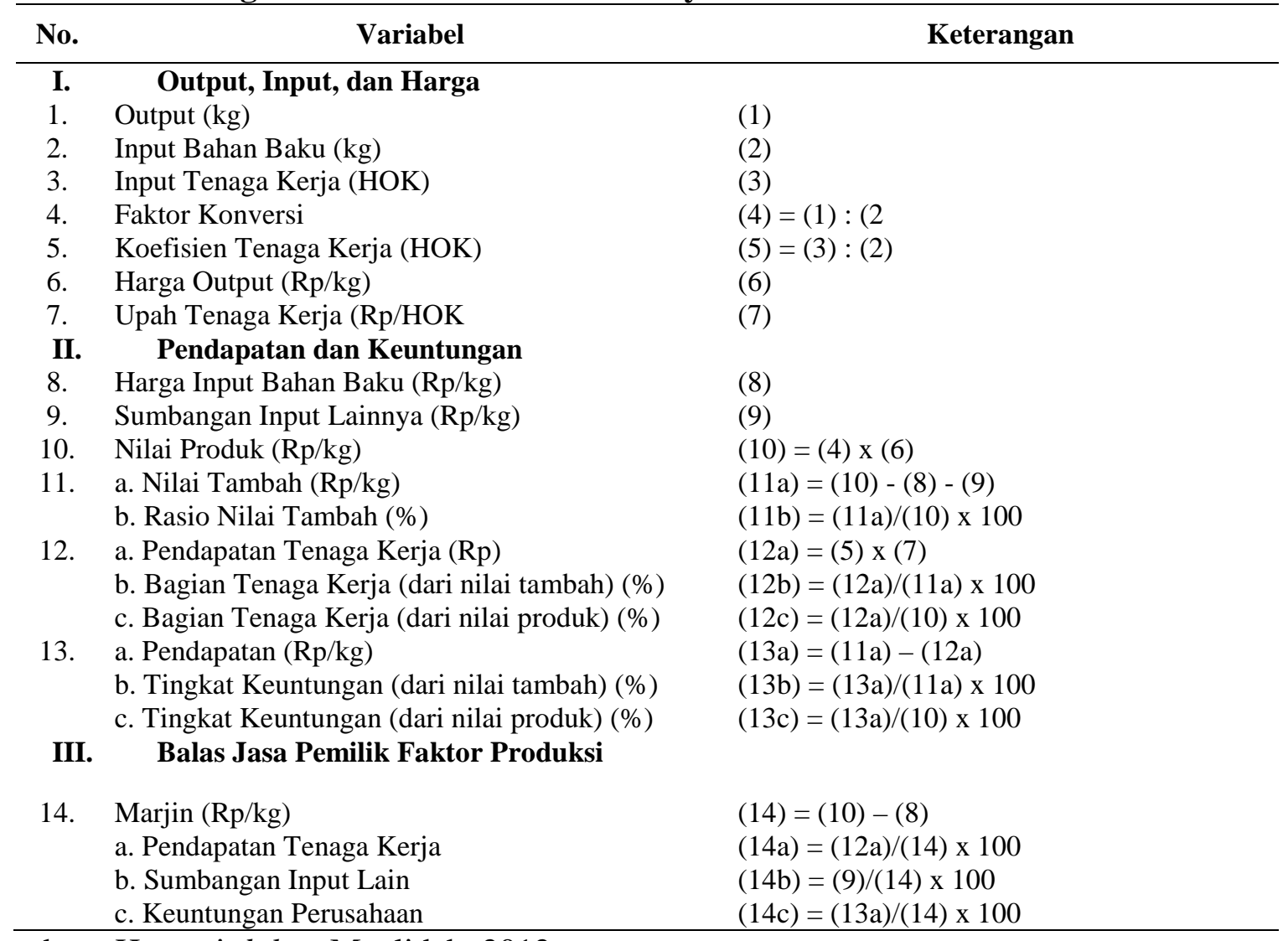

Sumber : Hayami dalam Maulidah, 2012

Kriteria nilai tambah (NT) adalah:

1) Jika NT $>0$, berarti usaha agroindustri tepung tapioka memberikan nilai tambah (positif).

2) Jika NT < 0 , berarti usaha agroindustri tepung tapioka tidak memberikan nilai tambah (negatif).

\section{HASIL DAN PEMBAHASAN}

\section{A. Penerimaan dan Pendapatan}

Penerimaan agroindustri tepung tapioka pada perusaahan "Tepung Tapioka "Madur" merupakan perkalian hasil produksi tepung tapioka dengan harga jual pada saat penelitian. Bahan baku ubi kayu yang digunakan sebanyak $10.000 \mathrm{~kg}$. Setelah ubi kayu diproduksi menghasilkan tepung tapioka dan onggok. Jumlah produk tepung tapioka yang dihasilkan dalam satu 
kali proses produksi yaitu sebanyak 2.480 $\mathrm{kg}$ dan ampas ubi kayu berupa onggok sebanyak $600 \mathrm{~kg}$. Jadi hasil bersih tepung tapioka yang dihasilkan dari $10.000 \mathrm{~kg}$ ubi kayu menghasilkan tepung tapioka sebanyak $2.480 \mathrm{~kg}$ dengan harga jual sebesar Rp $9.000 / \mathrm{kg}$.

Sehingga penerimaan dari penjualan tepung tapioka yang diperoleh pengusaha adalah Rp 22.320.000, kemudian ditambah dengan penjualan ampas onggok sebanyak $600 \mathrm{~kg}$ dengan harga jual sebesar Rp 400/kg, dan menghasilkan penerimaan sebesar $\mathrm{Rp}$ 240.000. Jadi total penerimaan yang diperoleh pengusaha dari agroindustri tepung tapioka adalah sebesar Rp 22.560 .000 .
Besarnya pendapatan atau keuntungan agroindustri tepung tapioka pada perusahaan "Tepung Tapioka Madur" diperoleh dari hasil pengurangan penerimaan dengan jumlah biaya produksi. Pendapatan yang diperoleh perusahaan agroindustri tepung tapioka dalam satu kali proses produksi adalah Rp 2.623.506.

\section{A. Perhitungan Nilai Tambah}

Merupakan hasil olahan pertanian dengan biaya, tidak termasuk biaya tenaga kerja. Analisis nilai tambah dihitung untuk mengetahui pertambahan tepung tapioka. Untuk menghitung nilai tambah tepung tapioka tersebut digunakan analisis nilai tambah dengan pendekatan struktur produksi (Maulidah, 2012). 
Tabel 3. Nilai Tambah Tepung Tapioka dalam Satu Kali Proses Produksi

\begin{tabular}{|c|c|c|}
\hline No. & Variabel & Keterangan \\
\hline I. & Output, Input, dan Harga & \\
\hline 1. & Output/Total Produksi (kg) & $2.480 \mathrm{~kg}$ \\
\hline 2. & Input Bahan Baku (kg) & $10.000 \mathrm{~kg}$ \\
\hline 3. & Input Tenaga Kerja (HOK) & $28 \mathrm{HOK}$ \\
\hline 4. & Faktor Konversi & 0,8 \\
\hline 5. & Koefisien Tenaga Kerja & 0,3 \\
\hline 6. & Harga Output $(\mathrm{Rp} / \mathrm{kg})$ & $9.000 / \mathrm{kg}$ \\
\hline 7. & Upah Tenaga Kerja (Rp/HOK) & 70.857 \\
\hline II. & Pendapatan dan Keuntungan & \\
\hline 8. & Harga Input Bahan Baku (Rp/kg) & $1.600 / \mathrm{kg}$ \\
\hline 9. & Sumbangan Input Lain $(\mathrm{Rp} / \mathrm{kg})$ & $10,28 / \mathrm{kg}$ \\
\hline 10. & Nilai Produk $(\mathrm{Rp} / \mathrm{kg})$ & $7.200 / \mathrm{kg}$ \\
\hline \multirow[t]{2}{*}{11.} & a. Nilai Tambah $(\mathrm{Rp} / \mathrm{kg})$ & $5.589 / \mathrm{kg}$ \\
\hline & b. Rasio Nilai Tambah (\%) & $77,6 \%$ \\
\hline \multirow[t]{3}{*}{12.} & a. Pendapatan Tenaga Kerja (Rp) & $1.417,14$ \\
\hline & b. Bagian Tenaga Kerja (dari nilai tambah) $(\%)$ & $25,3 \%$ \\
\hline & c. Bagian Tenaga Kerja (dari produk) $(\%)$ & $19,6 \%$ \\
\hline \multirow[t]{3}{*}{13.} & a. Keuntungan $(\mathrm{Rp} / \mathrm{kg})$ & $4.171,86 / \mathrm{kg}$ \\
\hline & b. Tingkat Keuntungan (dari nilai tambah) (\%) & $74,6 \%$ \\
\hline & c. Tingkat Keuntungan (dari nilai produk) $(\%)$ & $57,9 \%$ \\
\hline III. & Balas Jasa Pemilik Faktor Produksi & \\
\hline \multirow[t]{4}{*}{14.} & Marjin $(\mathrm{Rp} / \mathrm{kg})$ & $5600 / \mathrm{kg}$ \\
\hline & a. Pendapatan Tenaga Kerja & 25,3 \\
\hline & b. Sumbangan Input Lain & 0,18 \\
\hline & c. Pendapatan Perusahaan & 74,4 \\
\hline
\end{tabular}

Sumber Data Primer, Analisis Nilai Tambah Agroindustri Tepung Tapioka 2019

\section{KESIMPULAN DAN SARAN}

\section{Kesimpulan}

Berdasarkan hasil penelitian dan pembahasan, maka dapat diambil kesimpulan sebagai berikut :

1. Pengolahan tepung tapioka di agroindustri tepung tapioka "Madur" memperoleh keuntungan sebesar $\mathrm{Rp}$ 2.623.506 dalam satu kali proses produksi.

2. Diperoleh nilai tambah diperoleh pengusaha agroindustri tepung tapioka "Madur" yaitu sebesar Rp 5.589 per kilogram bahan baku dengan total produksi tepung tapioka sebanyak 2.480 kilogram dalam satu kali proses produksi. Rasio nilai tambah terhadap nilai produk sebesar $77,6 \%$. Artinya untuk setiap Rp 100 nilai produk akan diperoleh nilai tambah $\mathrm{Rp}$ 77. Nilai tambah menunjukkan nilai yang positif dan besar. Maka agroindustri tepung tapioka "Madur" sangat layak untuk diteruskan.

\section{Saran}

Berdasarkan hasil penelitian serta dilihat dari hasil pembahasan maka saran yang dapat disampaikan :

1. Pengusaha hendaknya harus tetap menjalankan dan mempertahankan produksi tepung tapioka tersebut karena memberikan keuntungan. 
2. Usaha agroindustri tepung tapioka memberikan nilai tambah dan manfaat bagi masyarakat sekitar karena dengan adanya perusahaan tersebut pendapatan masyarakat di Desa Bojongasih menjadi meningkat.

\section{DAFTAR PUSTAKA}

Departemen Pertanian, dalam Kurniaty, Edy Dwi. 2015. Kewirausahaan Industri. CV. Budi Utama. Yogyakarta.

Dinas Perindustrian dan Perdagangan. 2017. Data Agroindustri Tepung Tapioka di Kabupaten Tasikmalaya. Tasikmalaya.

Hambali, E. dkk. 2007. Teknologi Bioenergi. Agro Media Pustaka. Jakarta.

Hasanah, U. dkk. 2015. Analisis Nilai Tambah Agroindustri Sale Pisang di Kabupaten Kebumen. Ilmu Pertanian. Vol. 18 No. 3. Hal 141.

Hayami, dalam Maulidah. 2012. Tabel Perhitungan Nilai Tambah. Universitas Brawijaya (UB Press). Malang.

Herdiyandi, dkk. Analisis Nilai Tambah Agroindustri Tepung Tapioka di Desa Negaratengah Kecamatan Cineam Kabupaten Tasikmlaya. (Studi Kasud pada Seorang Pengusaha Agroindustri Tepung Tapioka di Desa Negaratengah Kecamatan Cineam Kabupaten Tasikmalaya. Jurnal Ilmiah Mahasiswa Agro Info Galuh Volume 2. No. 2. Fakultas Pertanian Universitas Galuh. Fakultas Pertanian Universitas Padjajaran.

Fakultas Pertanian Universitas Gadjah Mada.

Hick, dalam Sutrisno. 2015. Model Klaster dan Pengukuran Kinerja Sistem Agroindustri Kelapa Sawit di Su- matera Selatan. CV. Budi Utama. Yogyakarta.

Kartasasmita, M. 2011. Pengertian Agroindustri Menurut Pandangan Pribadi Serta Contoh Hasil Produk Agroindustri. Universitas Riau. Pekanbaru.

Kriyantono, Rachmat. 2006. Teknik Praktis Riset Komunikasi. Kencana Prenadana Media Group. Jakarta.

Maulidah, S. 2012. Pengantar Manajemen Agribisnis. Universitas Brawijaya (UB Press). Malang.

Mimi, H. dkk. 2017. Peranan Sektor Pertanian dalam Pembangunan Wilayah Kabupaten Bireuen Provinsi Aceh. Jurnal S.Pertanian. Vol. 1 No.3 Hal. 214.

Moleong, Lexy. 2007. Metodologi Penelitian Kualitatif. Remaja Rosdakarya. Bandung.

Pratiwi, A. dkk. 2015. Peran Agroindustri Hulu dan Hilir dalam perekonomian dan Distribusi Pendapatan di Indonesia. E. Journal. Hal. 130

Rahardjo, dan Gudnanto. 2011. Pemahaman Individu Teknik Non Tes. Nora Media Enterprise. Kudus.

Rahim, dan Hastuti. 2007. Ekonomika Pertanian. Penebar Swadaya. Jakarta.

Rukmana, R dan Yuniarsih. 2001. Aneka Olahan Ubi Kayu. Kanisius. Yogyakarta.

Setiawan, I. 2012. Agribisnis Kreatif (Pilar Wirausaha Masa Depan, Kekuatan Dunia Baru Menuju Kemakmuran Hijau). Penebar Swadaya. Jakarta.

Sihombing, M. 2014. Kinetika Hidrolisis Pembentukan Gula Pereduksi Dengan Pengaruh Variasi Konsentrasi HCL dan Temperatur Hidrolisis. Politeknik Negeri Sriwijaya. Palembang.

Sudiyono. 2004. Pemasaran Pertanian. UMM Press. Malang. 
Sugiyono. 2018. Metode Penelitian Kuantitatif, Kualitatif, dan $R \& D$. CV. Alfabeta. Bandung.

Sjamsir, Z. 2017. Pembangunan Pertanian dalam Pusaran Kearifan Lokal. CV. Sah Media. Makassar.

Suprapti, L. 2005. Tepung Tapioka Pembuatan dan Pemanfaatannya. Kanisius. Yogyakarta.

Suratiyah, K. 2015. Ilmu Usahatani. Penebar Swadaya. Jakarta.
Sutrisno. 2015. Manajemen Sumber Daya Manusia (Cetakan Ke Tujuh). Kencana Prenada Media Group.

Thamrin, M. dkk. 2013. Analisis Usahatani Ubi Kayu. Agrium. Vol. 18 No. 1. Hal. 57.

Victoria, Silitonga. Dkk. 2013. Nanas Menjadi Keripik dan Sirup. Fakultas Pertanian Sumatera Utara.

Zakaria, W.A. 2006. Ekonomi Makro Buku Ajar. Universitas Lampung. Bandar Lampung. 